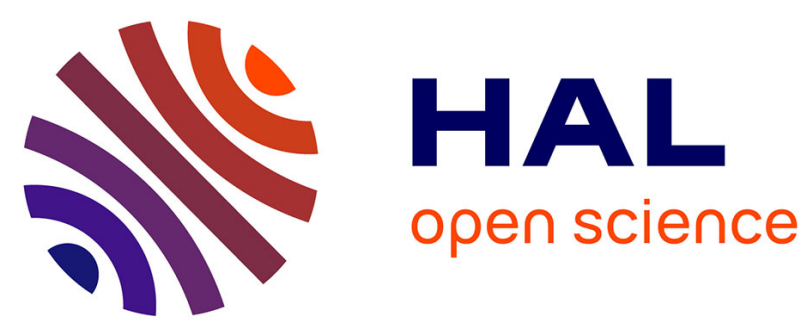

\title{
Improvement of phytoplankton culture isolation using single cell sorting by flow cytometry
}

Dominique Marie, Florence Le Gall, Roseline Edern, Priscillia Gourvil, Daniel Vaulot

\section{- To cite this version:}

Dominique Marie, Florence Le Gall, Roseline Edern, Priscillia Gourvil, Daniel Vaulot. Improvement of phytoplankton culture isolation using single cell sorting by flow cytometry. Journal of Phycology, 2017, 53 (2 ), pp.271-282 10.1111/jpy.12495 . hal-01408856

\section{HAL Id: hal-01408856 https://hal.sorbonne-universite.fr/hal-01408856}

Submitted on 5 Dec 2016

HAL is a multi-disciplinary open access archive for the deposit and dissemination of scientific research documents, whether they are published or not. The documents may come from teaching and research institutions in France or abroad, or from public or private research centers.
L'archive ouverte pluridisciplinaire HAL, est destinée au dépôt et à la diffusion de documents scientifiques de niveau recherche, publiés ou non, émanant des établissements d'enseignement et de recherche français ou étrangers, des laboratoires publics ou privés. 
Marie et al. - Culture isolation by flow cytometry sorting - p. 1

1

2

3

4

5

$6 \quad{ }^{1}$ Sorbonne Universités, UPMC Université Paris 06, CNRS, UMR7144, Station Biologique de

7 Roscoff, Roscoff, France.

$8 \quad 2$ Corresponding author: vaulot@ sb-roscoff.fr

9 Submitted to Journal of Phycology

10

Date : April 10, 2016

Daniel VAULOT ${ }^{1,2}$

\section{using single cell sorting by flow cytometry}

\author{
Daniel VAULOT
}

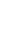

\section{Improvement of phytoplankton culture isolation}


Marie et al. - Culture isolation by flow cytometry sorting - p. 2

12

13

14

15

16

17

18

19

20

21

22

\section{Abstract}

Flow cytometry provides a tool to physically sort single algal cells in order to obtain clonal cultures. During sorting, cells are submitted to physical stress factors such as high fluidic pressure, exposure to the laser beam, electrostatic charges, deflection through high voltage fields and collisions with container surfaces. All of these can damage the cells of interest and success rates for initiation of cultures from flow-sorted cells are generally very low. We found that the addition of Bovine Serum Albumin (BSA) in the culture medium into which cells are sorted drastically improved the success of initiation of pico- and nano-eukaryotic phytoplankton strains. Adding a mixture of antibiotics (PNS: Penicillin, Neomycin, Streptomycin) to the medium in order to slow down bacterial growth further improved culture development. This approach was successfully used to isolate taxonomically diverse strains, including novel taxa, from a fresh sample obtained in the English Channel and from enrichment cultures established during an Atlantic Meridional Transect (AMT) cruise. We anticipate that these improvements will be useful to clone or purify existing cultures and to isolate novel cultures from oceanic samples.

Keywords: Flow cytometry, Single cell sorting, BSA, Picoeukaryotes, Nanoeukaryotes, Antibiotics, Microalgal cultures, Phytoplankton

Abbreviations : BSA, Bovine Serum Albumin; AMT, Atlantic Meridional Transect; PNS, Penicillin-Neomycin-Streptomycin; RCC, Roscoff Culture Collection; FSC, Forward Scatter; SSC, Side Scatter; DCM, Deep Chlorophyll Maximum; PCR; polymerase chain reaction; 
Marie et al. - Culture isolation by flow cytometry sorting - p. 3

\section{Introduction}

In the context of the rapid development of metabarcoding and metagenomics approaches to characterize marine microbial communities (de Vargas et al. 2015, Sunagawa et al. 2015), ex situ laboratory cultures are absolutely critical to provide reference sequences for marker genes such as 18S or 16S rRNA (Guillou et al. 2013, Decelle et al. 2015) or for genomes or transcriptomes (Keeling et al. 2014), thereby facilitating annotation of the massive datasets obtained. Many phytoplankton taxa are available in culture (del Campo et al. 2014), but culture isolation relies mostly on traditional approaches such as serial dilution or single cell pipetting (Andersen and Kawachi 2005). Novel methods are necessary to increase the diversity and number of microalgal strains available in culture.

Flow cytometry provides a rapid method for analysis of planktonic cells in both cultures and natural samples. Flow cytometry has been widely used to assess the abundance of autotrophic and heterotrophic oceanic microorganisms for over three decades (Olson et al. 1985, Marie et al. 1999, Zubkov et al. 2007). Some flow cytometry instruments are equipped with devices that allow sorting of cells based on their physical and biological characteristics. Flow cytometry sorting has been successfully applied to recover natural populations for genetic and genomic characterization (Shi et al. 2009, Woyke et al. 2009, Rinke et al. 2013), as well as for physiological measurements such as their capacity to fix carbon (Jardillier et al. 2010). However, this technique has relatively rarely been used to bring novel microorganisms into culture (Sensen et al. 1993, Sieracki et al. 2005, Sinigalliano et al. 2010, Cho et al. 2013), one reason for this being the generally low level of recovery of viable cultures after sorting.

Using ${ }^{14} \mathrm{C}$-uptake, Rivkin et al. (1986) showed that the passage of cells through a flow cytometer induces physiological damage to phytoplankton cells that results in a decrease in growth rate during the first days following sorting. These authors associated cell damage to high laser power, but found no effect of sheath fluid, droplet charging or sorting. Haugen et al. 
Marie et al. - Culture isolation by flow cytometry sorting - p. 4

(1987) did not find any physical damage or cell lysis due to fluidics or the laser beam, but reported a lag in growth for up to 48 hours after sorting, suggesting physiological damage. Sieracki et al. (2005) found higher recoveries when sorting single cells into 24- rather than 96well plates. However, while recovery of sorted Isochrysis, Rhodomonas, Scrippsiella and Thalassiosira varied from 22 to $99 \%$, single-cell sorting failed for the picoplanktonic green microalga Micromonas. Sinigalliano et al. (2010) found that the trauma due to automated cell sorting was not a limiting factor for obtaining unialgal dinoflagellate cultures compared to manual micropipetting. These reports emphasize the large taxon-specific variability in cell recovery after flow cytometry sorting.

The Roscoff Culture Collection (RCC) is one the largest service collections of marine microalgal cultures (Vaulot et al. 2004). In the last decade, we have placed considerable focus on using flow cytometry sorting to isolate unialgal cultures from natural samples (e.g. Le Gall et al. 2008, Balzano et al. 2012), but cell recovery has always been very low, especially when sorting single cells to obtain clonal cultures. In most cases, therefore, we have used flow cytometry sorting for cell enrichment rather than for single cell isolation. We have tested a range of solutions to try to obtain higher cell recovery such as lowering laser beam intensity, changing sheath pressure or deflection voltage, or adding chemicals such as EDTA that trap bivalent cations or Pluronic F68 that prevents adhesion of cells to the surfaces of plastic culture vessels (Marie et al. 2014). None of these attempts improved cell recovery in a consistent way (Marie, unpublished data).

In the present study we developed and tested a new protocol for strain isolation based on single cell sorting in culture medium supplemented with Bovine Serum Albumin (BSA) followed by antibiotic addition after a few days. This protocol was developed on cultures from the RCC and then tested on a fresh sample from the English Channel off Roscoff and on enrichment cultures obtained during an Atlantic Meridional Transect (AMT) cruise. In the latter case, we 
Marie et al. - Culture isolation by flow cytometry sorting - p. 5

84 compared flow cytometry sorting with more classical strain isolation approaches (serial dilution 85 and enrichment).

86 
Marie et al. - Culture isolation by flow cytometry sorting - p. 6

\section{Materials and methods}

Cultures. Five strains from different taxonomic groups were obtained from the Roscoff Culture Collection (RCC, www.roscoff-culture-collection.org): Micromonas pusilla RCC299 (Mamiellophyceae), Florenciella sp. RCC1008 (Dictyochophyceae), Isochrysis sp. RCC90 (Prymnesiophyceae), Rhodomonas baltica RCC350 (Cryptophyceae) and Scrippsiella sp. RCC4108 (Dinophyceae). Cultures were grown in K medium (Keller et al. 1987) in 12:12 hour light:dark cycle and were sorted when in exponential growth phase.

Oceanic samples. Surface seawater from the English Channel was sampled in May 2015 at the Estacade Station in Roscoff (Guilloux et al. 2013). A larger set of samples was obtained in 2014 during the Atlantic Meridional Transect (AMT, Rees et al. 2015) cruise \# 24 at two depths (surface and deep chlorophyll maximum, DCM). Twenty-two stations were sampled in the Atlantic Ocean between the United Kingdom and the Falkland Islands (Table 1 and Fig. 1). Precultures were obtained by adding $1 \mathrm{~mL}$ of $\mathrm{L} 1$ culture medium to $25 \mathrm{~mL}$ of seawater sample. Pre-cultures were maintained on board at $20^{\circ} \mathrm{C}$ in a L:D cycle and were transported promptly back to Roscoff at the end of the cruise.

Flow cytometry. A FACS Aria flow cytometer (Becton Dickinson, San Jose CA) equipped with 488 and $633 \mathrm{~nm}$ lasers and a standard filter setup was used for cell sorting. In order to minimize the impact of the laser, only the $488 \mathrm{~nm}$ laser was employed. Acquisition was triggered on red fluorescence, Forward Scatter (FSC) and Side Scatter (SSC) with the minimum threshold value. Sorting was performed in "single cell" mode using 20 PSI as sheath pressure. An Accuri C6 (Becton Dickinson, San Jose CA) equipped with a CSampler was used to monitor cell concentration after flow cytometry sorting. Acquisition was triggered on red fluorescence and performed for $1 \mathrm{~min}$ at a rate of $65 \mu \mathrm{L} / \mathrm{min}$. 
Marie et al. - Culture isolation by flow cytometry sorting - p. 7

110 Microscopy. An inverted microscope (Olympus IX71) equipped with epifluorescence (blue

111 light excitation, red light emission) was used to detect the presence of photosynthetic cells in

112 wells into which 1 cell was sorted. When cells with chlorophyll fluorescence were observed in

113 a well, it was considered as positive for culture growth.

114 Effect of BSA concentration on cultures. RCC cultures were sorted into $1 \mathrm{~mL}$ of K medium

115 either without BSA or with BSA (Ref A7030, Sigma) at concentrations of $0.01,0.1$ or $0.5 \%$.

116 Typically one 48-well plate (CytoOne, Starlab) was used for each culture: 1000 cells (500 for

117 Scripsiella) were sorted into 3 wells and 1 cell into each of the remaining 45 wells. Using the

118 Accuri C6, cell concentration was monitored over 2 weeks for the wells containing 500 or 1000

119 cells after sorting. Wells with 1 cell were monitored by epifluorescence microscopy between

120 days 3 and 14 following sorting.

121 Effect of antibiotic addition. RCC cultures were sorted into 48-well plates (CytoOne, Starlab) containing $1 \mathrm{~mL}$ of $\mathrm{K}$ medium supplemented with $0.01 \%$ BSA. For each culture 500 (Scripsiella) or 1000 (other strains) cells were sorted into 6 wells containing $1 \mathrm{~mL}$ of K medium.

124 Three days after sorting, a mixture of Penicillin, Neomycin and Streptomycin (PNS, Ref P4083, 125 Sigma) was added at a final concentration of $0.1 \%$ to 3 of the wells. Cell concentration was 126 subsequently monitored by flow cytometry for 2 weeks.

127 Effect of medium on sorting for a natural sample. Surface water from the English Channel

128 (see above) was filtered through a $50 \mu \mathrm{m}$ nylon mesh in order to remove larger cells that can 129 clog the flow cell of the cytometer. Four media supplemented with BSA $0.01 \%$ were tested: K 130 (Keller et al. 1987), f/2 (Ref G9903, Sigma, Guillard and Ryther 1962), water from the sampling 131 site supplemented with K medium nutrients (SW+Nut) and not supplemented (SW). All media 132 were filter-sterilized through a $0.2 \mu \mathrm{m}$ filter just before sorting. Two 48 -well plates containing

$1331 \mathrm{~mL}$ of medium per well were used per media tested, one for pico- and one for nano- 
Marie et al. - Culture isolation by flow cytometry sorting - p. 8

134 phytoplankton. The first 3 wells were used to sort 1000 cells for the pico-phytoplankton and

135500 cells for the nano-phytoplankton, respectively. One cell was sorted in each of the remaining

13645 wells. Three days after sorting, PNS $0.1 \%$ (final concentration) was added into all wells with

1371000 or 500 sorted cells and cell concentration was monitored over 2 weeks by flow cytometry

138 (Fig. 2). Wells with 1 sorted cell were monitored by epifluorescence microscopy every three

139 days for 2 weeks following sorting. When live cells were observed in a well, PNS $0.1 \%$ (final

140 concentration) was added. Ten diatom strains isolated during this experiment were kept in

141 culture and incorporated into the RCC.

142 Oceanic strain isolation. Three different isolation approaches were compared using pre-

143 cultures obtained during the AMT 2014 cruise (see above): flow cytometry sorting, enrichment

144 and serial dilution.

145 For flow cytometry sorting, 24 AMT pre-cultures were sorted in $1 \mathrm{~mL}$ of $\mathrm{K}$ medium with $0.01 \%$

146 BSA into 48-well plates (Table 1). Half a plate was used for each population selected: 1000

147 cells were sorted into the first two wells, 100 into the next two wells as controls and 1 cell into

148 the remaining 20 wells. Plates were incubated in a,12:12 light:dark cycle for 10 days. Wells

149 were then screened by inverted epifluorescence microscopy to detect the presence of

150 photosynthetic cells. When live cells were observed in the wells with 1 sorted cell, they were

151 transferred into a tube containing $5 \mathrm{~mL}$ of $\mathrm{K}$ medium supplemented with a final concentration

152 of $0.1 \%$ PNS.

153 For enrichment, AMT pre-cultures were screened and counted by flow cytometry. When the

154 pre-culture seemed to contain only one population of cells, the isolation technique used was an

155 enrichment in the appropriate culture medium. This technique was used for 19 pre-cultures from

156 AMT (Table 1). We used K medium for eukaryotes and PCRS11 medium (Rippka et al. 2000)

157 for cyanobacteria. 
158 For dilution, AMT pre-cultures were screened and counted by flow cytometry. Fifteen pre-

159 cultures that contained several cell populations with different sizes and chlorophyll signals were

160 diluted into K medium in 48-well plates. Eight wells were used for each pre-culture with a final

161 target density of 10 cells per well (Table 1). Plates were incubated in a 12:12 light:dark cycle

162 for 3 weeks, after which an inverted epifluorescence microscope was used to check for the

163 presence of cells.

164

165 Strain characterization. Strains were characterized by sequencing partially the $18 \mathrm{~S}$ rRNA

166 gene. The cells were heated for $5 \mathrm{~min}$ at $95^{\circ} \mathrm{C}$ and cooled to $4^{\circ} \mathrm{C}$. The $18 \mathrm{~S}$ rRNA gene was

167 amplified by polymerase chain reaction (PCR) using the eukaryote specific primers $63 \mathrm{~F} / 1818 \mathrm{R}$

168 (Lepère et al. 2011) and the Phusion Master Mix (Thermo Fisher Scientific, France). For PCR,

169 a 5 minute initial denaturation step at $95^{\circ} \mathrm{C}$ was followed by 35 cycles including 1 min of

170 denaturation at $95{ }^{\circ} \mathrm{C}, 90 \mathrm{sec}$ of annealing at $57^{\circ} \mathrm{C}$ and $90 \mathrm{sec}$ extension at $72^{\circ} \mathrm{C}$. The PCR

171 program was finished by a final extension of $10 \mathrm{~min}$ at $72^{\circ} \mathrm{C}$ followed by cooling at $4^{\circ} \mathrm{C}$. PCR

172 products were purified using Exosap (USB products, Santa Clara, USA). Partial 18S rRNA

173 gene sequences were determined by using Big Dye Terminator V3.1 (Applied Biosystems,

174 Foster city, CA, USA) and the internal primer Euk 528f (Elwood et al. 1985). Sequencing was

175 carried out on an ABI prism 3100 sequencer (Applied Biosystems). Partial 18S rRNA

176 sequences were compared to those available in public databases with NCBI BLAST

177 (blast.ncbi.nlm.nih.gov/Blast.cgi).

178 All AMT strains and 10 strains isolated from the English Channel have been deposited in the

179 Roscoff Culture Collection (RCC4548 to RCC4579 and RCC4657 to RCC4666, respectively)

180 and their sequences deposited in GenBank under accession numbers KX014627-KX014660. 
Marie et al. - Culture isolation by flow cytometry sorting - p. 10

183

184

185

186

187

188

189

190

191

192

193

194

195

196

197

198

199

200

201

202

203

204

205

\section{Results}

\section{Effect of BSA addition.}

We first tested the effect of adding BSA at different concentrations $(0,0.1,0.01$ and $0.05 \%)$ to the culture medium into which cells were sorted using 5 strains of eukaryotes (Fig. 2 and Table 2).

For the picoplanktonic strain Micromonas pusilla (Mamiellophyceae) RCC299, we observed a rapid decline in cell concentration for the 3 wells with 1000 sorted cells in the absence of BSA and no live cells were detected by flow cytometry after 5 days of incubation (Fig. 2A). After 8 days, cells were detected in 2 of the 3 wells. In presence of BSA, no lag phase or decline in cell numbers were observed. Initial growth rates were identical for the three BSA concentrations tested, but after 5 days of incubation better growth was obtained at the lowest BSA concentration $(0.01 \%)$. Epifluorescence microscope observations of wells into which 1 cell was sorted (Table 2) revealed the absence of cells in the absence of BSA, $100 \%$ recovery with $0.01 \%$ BSA, and 50 to $60 \%$ recovery with 0.1 and $0.5 \%$, respectively.

In the absence of BSA and at the two lowest BSA concentrations $(0.01$ and $0.1 \%)$, the other picoplanktonic strain Florenciella sp. RCC1008 (Dictyochophyceae) decreased in abundance during the first week and no cells were detected 10 days after sorting (Fig. 2B). Between days 10 and 14, cell abundance recovered slowly. In wells with the highest BSA concentration $(0.5 \%)$, cell abundance did not decrease significantly and we observed exponential growth after day 7 (Fig. 2B). For single sorted cells of this strain, no recovery was detected at the lowest BSA concentration $(0.01 \%)$. In the absence of BSA and at $0.1 \%$ BSA, 1 and 2 wells, respectively, exhibited growth after 2 weeks. In wells with the highest BSA concentration $(0.5 \%)$, growth was detected in 7 out of 9 wells at day 14 (Table 2). 
Marie et al. - Culture isolation by flow cytometry sorting - p. 11

206 BSA did not affect growth of the nanoplanktonic strains Isochrysis sp. RCC90 207 (Prymnesiophyceae) and Rhodomonas baltica RCC350 (Cryptophyceae) (Fig. 2C and D). For 208 Isochrysis, growth was observed after day 5 in some wells with 1 cell and all wells had growing 209 cultures by the end of the experiment for all BSA concentrations (Table 2). For Rhodomonas, 210 growth was observed in almost all wells at day 3 (Table 2).

211 For Scrippsiella sp. RCC4108 (Dinophyceae), a small decrease in cell number was observed 212 immediately after sorting of 500 cells in the absence of BSA (Fig. 2E). However, growth rate 213 was very similar in all four conditions. After day 7, cell number was highest with BSA $0.01 \%$ 214 and lowest with BSA $0.1 \%$. No effect of BSA was observed for single sorted cells of this strain. 215 The maximum number of wells with detectable growth was obtained on day 3 in the absence 216 of BSA (5/9) and there was no evolution in the number of positive wells past day 7 (Table 2).

\section{Effect of antibiotic treatment.}

218 For cultures sorted into medium with $0.01 \%$ BSA, growth stopped after 4 days for Scrippsiella and 7 days for Micromonas and Rhodomonas in the absence of the antibiotic cocktail (PNS),

220 while cultures continued to grow when PNS was added (Fig. 3). Isochrysis had a higher growth 221 rate in the absence of PNS reaching stationary phase earlier than with PNS, although after 2 weeks cell yield was similar. For Florenciella, addition of PNS resulted in significant cell loss, but cultures recovered one week after sorting to reach a higher final density than in the absence 224 of PNS (Fig. 3)

\section{Recovery and isolation of phytoplankton sorted from a fresh seawater sample}

226 Wells into which 1000 picoeukaryote cells were sorted had similar growth rates irrespective of 227 the medium, but final cell concentration was lower in $\mathrm{f} / 2$ and unamended seawater (Fig. 4A). 228 Single picoeukaryote sorted cells began to grow in some wells after 3 days and the percentage of wells with detectable growth after 2 weeks was highest using f/2 medium, reaching almost 
Marie et al. - Culture isolation by flow cytometry sorting - p. 12

$100 \%$, followed by amended SW, SW and K medium for which recovery was only $50 \%$ (Table 3). After 9 to 15 days, approximatively $70 \%$ of wells containing f/2 or SW with nutrients and only $30 \%$ for SW or K medium were dense enough to allow transfer to tubes containing $4 \mathrm{~mL}$ of $\mathrm{K}$ medium. All strains obtained from single cell sorting (Table 4) were Chlorophyta representing two classes, the Mamiellophyceae (Micromonas, Ostreococcus and Bathycoccus) and the Trebouxiophyceae (Picochlorum). The highest number of different genera was obtained using $\mathrm{f} / 2$ medium and the lowest in unamended seawater.

No difference in growth rate was observed after sorting 500 nanoeukaryote cells in different media, but after 6 days, cell numbers were significantly higher in wells with f/2 and SW+Nut (Fig. 4B). Heterogeneity in cell numbers was observed among the 3 wells in all media. As for picoeukaryotes, cells were detected in some single-cell wells after only 3 days (Table 3) and the number of wells with detectable growth did not increase beyond day 9. More than half of the wells yielded growth and this proportion was highest with SW (71\%) and lowest with K, as was the case for picoeukaryotes. Strains obtained from single cell sorting were mostly small(Minidiscus, Minutocellus) or medium-sized (Thalassiosira, Skeletonema, Cylindrotheca) diatoms, or the common prymnesiophyte Phaeocystis (Table 4). The largest variety of genera was obtained using amended SW and the lowest using K, as was the case for picoeukaryotes.

\section{Isolation of phytoplankton strains from oceanic enrichments}

During AMT cruise \#24, from the UK to the Falkland Islands, two depths (surface and DCM) were sampled at a range of stations in the Atlantic Ocean from temperate to equatorial environments. During the cruise, pre-cultures were obtained by adding L1 medium to natural samples and these pre-cultures were promptly brought back to the laboratory at the end of the cruise. Single-cell flow cytometry sorting was applied to 24 pre-cultures using K medium with 0.01\% BSA, yielding a total of 700 wells (Table 1). After 10 days of incubation, phytoplankton growth was observed in $278(40 \%)$ wells. The percentage of wells with growth varied with the 
255 pre-culture, ranging from $0 \%$ to $100 \%$ (Table 1). Positive wells were transferred into tubes 256 containing $5 \mathrm{~mL}$ of $\mathrm{K}$ medium supplemented with a final concentration of $0.01 \%$ PNS.

257 In parallel, we prepared 120 wells by serial dilution from 15 pre-cultures ( 8 wells per pre258 culture) with a target concentration of 10 cells per well. After 3 weeks of incubation, 39 (33\%) 259 wells showed positive growth (Table 1). As for sorting, the success rate was variable, again 260 ranging from 0 to $100 \%$ depending on the pre-culture (Table 1). Cells from positive wells were 261 transferred into tubes using K medium for eukaryotes and PCR-S11 for cyanobacteria. Finally, 262 a simple enrichment approach was performed on nineteen pre-cultures using different media 263 and sixteen cultures were isolated in this manner.

264 Genetic characterization of the AMT strains using the 18S rRNA gene revealed that many 265 cultures belonged to the same genus. For cultures obtained either by flow cytometry sorting or 266 dilution, all tubes originating from the same pre-culture and obtained with the same technique 267 yielded identical sequences. For example, the 36 positive wells originating from pre-culture 04 268 (Table 1) were all affiliated to Phaeocystis. When we obtained the same affiliation with the 3 269 techniques of isolation, we decided to prioritize maintenance of the cultures isolated by flow 270 cytometry sorting because these strains were more likely to be clonal. In total, 31 representative 271 cultures were deposited to the RCC, corresponding to 11 different genera (Table 5). The highest 272 diversity was obtained with cell sorting, but some taxa were only obtained by dilution or 273 enrichment (Table 6). The genera isolated from the largest number (8) of pre-cultures (Table 274 6) belonged to Pelagophyceae (Pelagomonas) and Cyanophyceae (Synechococcus), although 275 the latter were only isolated by dilution or enrichment since only eukaryotes were targeted by 276 sorting. Strains isolated from more than one pre-culture belonged to the Chlorophyta 277 (Micromonas, prasinophyte clade VII), Prymnesiophyceae (Phaeocystis, Emiliania, Isochrysis) 278 and Pelagophyceae. Finally some strains were only isolated from a single pre-culture. This 
Marie et al. - Culture isolation by flow cytometry sorting - p. 14

was in particular the case for RCC4570, the 18S rRNA sequence of which was affiliated to the Heterokontophyta.

\section{Discussion}

Isolation of phytoplankton strains from oceanic waters is a difficult task because many taxa have unknown nutritional requirements or are quickly outcompeted by fast growing species. For small cells (pico- and nano-phytoplankton), the most common approach involves serial dilution (Andersen and Kawachi 2005) using media such as $\mathrm{K}$ which have been specifically designed for oceanic strains (Keller et al. 1987). However, this strategy is blind and provides random results since no specific group is targeted. For example, during the BIOSOPE cruise in the South East Pacific, serial dilution resulted in isolation of 34 strains of Pelagomonas calceolata (Le Gall et al. 2008), but did not recover any of the dominant taxa in this region that belong to the haptophyte, chrysophyte and prasinophyte clade IX lineages (Shi et al. 2009). The theoretical advantages of flow cytometry include the possibility of targeting specific groups based on their size and chlorophyll content, as well as the capacity to isolate single cells, resulting in clonal cultures. The former factor should allow elimination of fast growing species that tend to be over-represented when using other techniques. However, as outlined above, success rates for culture recovery have been very low for single cell flow cytometric sorting.

While trying different additions to sorting medium, we discovered that BSA had a spectacular impact on cell recovery. The reason for the positive effect of BSA is unclear. Albumin is a major protein from bovine or human serum, with multifunctional properties and is widely used for mammalian cell cultures (Francis 2010). It is well known as a strong antioxidant and has also been proved to avoid attachment of cells onto plastic walls (Fletcher 1976). BSA is also often added when preparing protoplasts from macroalgae (e.g. Bodian et al. 2013). Unfortunately, no detailed study on its effect or role on cell culture has been published. Of the five strains tested in the present study belonging to a range of phylogenetic groups, the 
Marie et al. - Culture isolation by flow cytometry sorting - p. 15

nanoplanktonic strains Isochrysis, Rhodomonas and Scrippsiella recovered well after sorting and BSA did not seem to have a significant effect except in the case of Scrippsiella for which the lag phase was reduced with BSA addition (Fig. 2C-E and Table 2). In contrast, the picoplanktonic species Micromonas and Florenciella could not recover after sorting without the addition of BSA (Fig. 2A-B and Table 2), confirming the report of Sieracki et al. (2005) who did not obtain any growth of Micromonas when sorting 1 cell per well. With addition of BSA, we obtained 100\% regrowth of Micromonas (Table 2). Interestingly, the optimum BSA concentration varied with the species. While concentrations below $0.5 \%$ had no effect on Florenciella (Fig. 2 and Table 2), 0.01\% was optimum for Micromonas (Fig. 2 and Table 2). This suggests that it will be necessary to test different BSA concentrations when dealing with specific cultures or natural populations. In particular, Florenciella, which apparently requires a high BSA concentration to facilitate regrowth after single cell sorting, has rarely been isolated into culture: there are only 11 strains isolated from 3 cruises available in culture collections (all in the RCC).

When using flow cytometry to sort phytoplankton cells from natural samples, heterotrophic bacteria are also likely to be sorted since they often outnumber phototrophic cells by an order of magnitude. Although flow cytometry has been used to produce axenic cultures (Sensen et al. 1993), it is difficult to completely remove associated bacteria, especially those that adhere to the surface of microalgal cells (Surek and Melkonian 2004), and antibiotics are often necessary to obtain axenic cultures (Cottrell and Suttle 1993). Even when axenic cultures are not targeted, antibiotic treatment may be critical to reduce competition for nutrients from bacteria. This was apparently the case for Micromonas, Rhodomonas and Scrippsiella which stopped growing after a few days in the absence of antibiotics, while growth continued when PNS was added (Fig. 3A, D, E). The case of Florenciella was paradoxical. Addition of PNS led to an initial decrease of cell concentration which then recovered after day 7, while in the absence of PNS 
Marie et al. - Culture isolation by flow cytometry sorting - p. 16

329 initial growth was continuous but final cell density was ten times lower. This could be 330 explained by Florenciella being mixotrophic, as reported for field populations (Frias-Lopez et 331 al. 2009). The initial decrease of the population when antibiotics were added could therefore 332 be due to the decrease in bacterial prey density, followed by a switch to autotrophic nutrition 333 inducing regrowth.

334 Another factor to take into account during isolation of phytoplankton strains is the composition 335 of the culture medium. Very few studies have assessed the effect of different media on the 336 success of culture isolation or even on culture growth. Harrison and Berges (2005) quoted 337 McLachlan (1973): "Numerous enriched and synthetic media have been formulated, which 338 together with generally trivial modifications, almost equal the number of investigators". The 339 two most commonly used media for marine microalgae are f/2 (Guillard and Ryther 1962) and $340 \mathrm{~K}$ (Keller et al. 1987). The effect of these two media along with unamended and amended sea 341 water was tested using a fresh sample from the English Channel (Tables 3 and 4). For 342 picoeukaryotes, the use of $\mathrm{f} / 2$ resulted in the widest diversity of strains, while for 343 nanoeukaryotes differences were less marked. This could be explained by the fact that $\mathrm{f} / 2$ is 344 more appropriate for coastal species (Keller et al. 1987). However, some species, such as 345 Ostreococcus, Phaeocystis, Minidiscus and Thalassiosira, were always isolated irrespective of 346 the medium used. Our approach allowed isolation from a single sample of three picoplanktonic 347 genera, Micromonas, Ostreococcus and Bathycoccus, that are dominant in English Channel 348 coastal waters as demonstrated previously both by fluorescent in situ hybridization (FISH) and 349 18S rRNA clone libraries (Not et al. 2004, Romari and Vaulot 2004, Marie et al. 2010). The 350 nanoplanktonic species isolated were mostly diatoms reflecting the fact that the sample was 351 taken during the spring diatom bloom (Sournia et al. 1987).

352 Our protocol proved to be efficient for obtaining clonal strains from pre-cultures established 353 during an Atlantic cruise. In particular, we repeatedly obtained strains of Pelagomonas and 
Marie et al. - Culture isolation by flow cytometry sorting - p. 17

354 prasinophyte clade VII, both of which are typically isolated from oceanic tropical and sub355 tropical waters (Le Gall et al. 2008). We obtained strains of several taxa that, to our knowledge, 356 have not previously been cultured. Within prasinophyte clade VII, we obtained for the first 357 time a representative of clade VIIB3 (Lopes dos Santos et al., submitted). In addition, three 358 Pelagophyceae cultures corresponded to undescribed taxa. The $18 \mathrm{~S}$ rRNA sequences of two 359 Pelagophyceae strains from the tropical Atlantic (RCC4562 and RCC4563) matched with 100\% 360 identity the sequence of RCC1024, previously isolated from the South East Pacific (Le Gall et al. 2008). These strains are also related to the endosymbiont of the tropical dinoflagellate Amphisolenia bidentata (Daugbjerg et al. 2013). Strain RCC4552, isolated from the temperate North Atlantic, had a sequence only $98.7 \%$ similar to any other GenBank sequence and probably corresponds to a novel species. Its sequence was most closely related to RCC2505, isolated from polar waters (Balzano et al. 2012). The 18S rRNA sequence of RCC4570, a stramenopile strain obtained by dilution, was related to two strains (RCC853 and RCC862) that had been previously isolated from the South East Pacific (Le Gall et al. 2008), but unfortunately lost since. This group of sequences suggests the existence of a novel algal class, called MOCH5 by Massana et al. (2014). As evident from Table 1, the success of the three approaches we used (sorting, dilution, enrichment) was highly variable. In several cases only one technique was successful for a given pre-culture: for example, strains were obtained by dilution but not sorting for pre-cultures 26,27 and 42, whereas the opposite result was obtained for pre-cultures 54 and 55.

374 The novel protocol proposed for culture isolation using single-cell flow cytometry sorting has 375 several advantages compared to other techniques for culture isolation. It is much more rapid 376 than serial dilution. A 48-well plate can be sorted in less than 1 minute. Results are obtained 377 in less than 10 days, compared to at least three weeks for serial dilution. More importantly, 378 specific populations can be targeted. For example, many of our AMT serial dilution wells 
Marie et al. - Culture isolation by flow cytometry sorting - p. 18

produced untargeted Synechococcus cultures, while sorting targeted only eukaryotes. Flow cytometry sorting is best done on fresh samples since the diversity of the taxa recovered is high and more representative of the initial diversity, as demonstrated for an English Channel sample obtained near our laboratory from which we isolated at least 10 different taxa. However, this requires the availability of a bulky sorting flow cytometer near the sampling site or on the cruise. An alternative strategy for large scale cruises is to enrich samples to obtain pre-cultures. This can be done many different ways, without or with filtration in order to select specific size classes, without or with tangential flow filtration which allows concentration of samples, or with a range of different media and additives, such as germanium dioxide to prevent diatom growth (Vaulot et al. 2004, Le Gall et al. 2008, Balzano et al. 2012). In such cases, since there can be a long delay before the pre-cultures can be sorted, each pre-culture usually becomes dominated by one or two species. Single-cell sorting allows rapid purification and cloning of these pre-cultures as demonstrated for the AMT cruise. Since diversity is typically rather low for a given pre-culture, a relevant strategy to obtain different taxa in culture is to apply sorting to a large number of pre-cultures originating from different stations and depths (Table 5).

Another useful application of this protocol would be to make existing cultures clonal. We recently applied this approach to clone RCC strains of Micromonas, Ostreococcus, Bathycoccus and Triparma (PG, unpublished data). It can also be used to purify mixed cultures, in which case there is no need to perform single cell sorting; sorting of several hundred cells for each target population should provide good results.

\section{Acknowledgments}

We thank Monica Moniz and Dave Scanlan from Warwick University for providing samples from the AMT 2014 cruise \#24 as well as Ian Probert for his help improving the English language. Financial support for this work was provided by the European Union's 7th Framework Programme MaCuMBA project (FP7-KBBE-2012-6-311975) and the Betty and 
Marie et al. - Culture isolation by flow cytometry sorting - p. 19

404 Gordon Moore Foundation (MMI EMS grant \#4972). The publication reflects the views only 405 of the author, and the European Union cannot be held responsible for any use which may be 406 made of the information contained therein. 


\section{References}

Andersen, R.A. \& Kawachi, M. 2005. Traditional microalgae isolation techniques. In Andersen, R. A. [Ed.] Algal Culturing Techniques. Elsevier/Academic Press, Amsterdam, pp. 83100.

Balzano, S., Gourvil, P., Siano, R., Chanoine, M., Marie, D., Lessard, S., Sarno, D. et al. 2012. Diversity of cultured photosynthetic flagellates in the North East Pacific and Arctic Oceans in summer. Biogeosciences. 9:4553-71.

Bodian, M.Y., Lafontaine, N., Matard, M., Mussio, I. \& Rusig, A.M. 2013. Evaluation of the in vitro methods for micropropagation of Chondracanthus acicularis (Roth) Fredericq (Gigartinales, Rhodophyta): Tissue culture and production of protoplasts. J. Appl. Phycol. 25:1835-45.

Cho, D.H., Ramanan, R., Kim, B.H., Lee, J., Kim, S., Yoo, C., Choi, G.G. et al. 2013. Novel approach for the development of axenic microalgal cultures from environmental samples. J. Phycol. 49:802-10.

Cottrell, M.T. \& Suttle, C.A. 1993. Production of axenic cultures of Micromonas pusilla (Prasinophyceae) using antibiotic. J. Phycol. 29:385-7.

Daugbjerg, N., Jensen, M.H. \& Hansen, P.J. 2013. Using nuclear-encoded LSU and SSU rDNA sequences to identify the eukaryotic endosymbiont in Amphisolenia bidentata (Dinophyceae). Protist. 164:411-22.

de Vargas, C., Audic, S., Henry, N., Decelle, J., Mahe, F., Logares, R., Lara, E. et al. 2015. Eukaryotic plankton diversity in the sunlit ocean. Science. 348:1261605.

Decelle, J., Romac, S., Stern, R.F., Bendif, E.M., Zingone, A., Audic, S., Guiry, M.D. et al. 2015. PhytoREF: a reference database of the plastidial 16S rRNA gene of photosynthetic eukaryotes with curated taxonomy. Mol. Ecol. Resour. 15:1435-1445.

del Campo, J., Sieracki, M.E., Molestina, R., Keeling, P., Massana, R. \& Ruiz-Trillo, I. 2014. The others: our biased perspective of eukaryotic genomes. Trends Ecol. Evol. 29:252-9.

Elwood, H.J., Olsen, G.J. \& Sogin, M.L. 1985. The small-subunit ribosomal RNA gene sequences from the hypotrichous ciliates Oxytricha nova and Stylonychia pustulata. Mol. Biol. Evol. 2:399-410.

Fletcher, M. 1976. The effects of proteins on bacterial attachment to polystyrene. J. Gen. Microbiol. 94:400-4.

Francis, G.L. 2010. Albumin and mammalian cell culture: implications for biotechnology applications. Cytotechnology. 62:1-16.

Frias-Lopez, J., Thompson, A., Waldbauer, J. \& Chisholm, S.W. 2009. Use of stable isotopelabelled cells to identify active grazers of picocyanobacteria in ocean surface waters. Environ. Microbiol. 11:512-25.

Guillard, R.R.L. \& Ryther, J.H. 1962. Studies of marine diatoms. I. Cyclotella nana Husdedt and Detonula confervacea Gran. Can. Jounal Microbiol. 8:229-39.

Guillou, L., Bachar, D., Audic, S., Bass, D., Berney, C., Bittner, L., Boutte, C. et al. 2013. The Protist Ribosomal Reference database (PR2): a catalog of unicellular eukaryote Small SubUnit rRNA sequences with curated taxonomy. Nucleic Acids Res. 41:D597-604. 
Guilloux, L., Rigaut-Jalabert, F., Jouenne, F., Ristori, S., Viprey, M., Not, F., Vaulot, D. et al. 2013. An annotated checklist of Marine Phytoplankton taxa at the SOMLIT-Astan time series off Roscoff (Western Channel, France): data collected from 2000 to 2010. Cah. Biol. Mar. 54:247-56.

Harrison, P.J. \& Berges, J.A. 2005. Marine Culture Media. In Andersen, R. A. [Ed.] Algal Culturing Techniques. Academic Press, Amsterdam, pp. 21-33.

Haugen, E.M., Cucci, T.L., Yentsch, C.M. \& Shapiro, L.P. 1987. Effects of flow cytometric analysis on morphology and viability of fragile phytoplankton. Appl. Environ. Microbiol. 53:2677-9.

Jardillier, L., Zubkov, M. V, Pearman, J. \& Scanlan, D.J. 2010. Significant CO2 fixation by small prymnesiophytes in the subtropical and tropical northeast Atlantic Ocean. ISME J. 4:1180-92.

Keeling, P.J., Burki, F., Wilcox, H.M., Allam, B., Allen, E.E., Amaral-Zettler, L.A., Armbrust, E.V. et al. 2014. The Marine Microbial Eukaryote Transcriptome Sequencing Project (MMETSP): illuminating the functional diversity of eukaryotic life in the oceans through transcriptome sequencing. PLoS Biol. 12:e1001889.

Keller, M.D., Selvin, R.C., Claus, W. \& Guillard, R.R.L. 1987. Media for the culture of oceanic ultraphytoplankton. J. Phycol. 23:633-8.

Le Gall, F., Rigaut-Jalabert, F., Marie, D., Garczareck, L., Viprey, M., Godet, A. \& Vaulot, D. 2008. Picoplankton diversity in the South-East Pacific Ocean from cultures. Biogeosciences. 5:203-14.

Lepère, C., Demura, M., Kawachi, M., Romac, S., Probert, I. \& Vaulot, D. 2011. Whole Genome Amplification (WGA) of marine photosynthetic eukaryote populations. FEMS Microbiol. Ecol. 76:516-23.

Marie, D., Brussaard, C.P.D., Partensky, F. \& Vaulot, D. 1999. Flow cytometric analysis of phytoplankton, bacteria and viruses. In Robinson, J. P. [Ed.] Current Protocols in Cytometry. John Wiley \& Sons, New York, pp. 1-15.

Marie, D., Rigaut-Jalabert, F. \& Vaulot, D. 2014. An improved protocol for flow cytometry analysis of phytoplankton cultures and natural samples. Cytometry. 85:962-8.

Marie, D., Shi, X.L., Rigaut-Jalabert, F. \& Vaulot, D. 2010. Use of flow cytometric sorting to better assess the diversity of small photosynthetic eukaryotes in the English Channel. FEMS Microbiol. Ecol. 72:165-78.

Massana, R., del Campo, J., Sieracki, M.E., Audic, S. \& Logares, R. 2014. Exploring the uncultured microeukaryote majority in the oceans: reevaluation of ribogroups within stramenopiles. ISME J. 8:854-66.

Not, F., Latasa, M., Marie, D., Cariou, T., Vaulot, D. \& Simon, N. 2004. A single species Micromonas pusilla (Prasinophyceae) dominates the eukaryotic picoplankton in the western English Channel. Appl. Environ. Microbiol. 70:4064-72.

Olson, R.J., Vaulot, D. \& Chisholm, S.W. 1985. Marine phytoplankton distributions measured using shipboard flow cytometry. Deep - Sea Res. Part A. Oceanogr. Res. Pap. 32:127380 .

Rees, A., Robinson, C., Smyth, T., Aiken, J., Nightingale, P. \& Zubkov, M. 2015. 20 Years of the Atlantic Meridional Transect-AMT. Limnol. Oceanogr. Bull. 
Rinke, C., Schwientek, P., Sczyrba, A., Ivanova, N.N., Anderson, I.J., Cheng, J.-F., Darling, A.E. et al. 2013. Insights into the phylogeny and coding potential of microbial dark matter. Nature. 499:431-7.

Rippka, R., Coursin, T., Hess, W., Lichtle, C., Scanlan, D.J., Palinska, K.A., Iteman, I. et al. 2000. Prochlorococcus marinus Chisholm et al. 1992 subsp. pastoris subsp. nov. strain PCC 9511, the first axenic chlorophyll a2/b2-containing cyanobacterium (Oxyphotobacteria). Int. J. Syst. Evol. Microbiol. 50:1833-47.

Rivkin, R.B., Phinney, D.A. \& Yentsch, C.M. 1986. Effects of flow cytometric analysis and cell sorting on photosynthetic carbon uptake by phytoplankton in cultures and from natural populations. Appl. Environ. Microbiol. 52:935-8.

Romari, K. \& Vaulot, D. 2004. Composition and temporal variability of picoeukaryote communities at a coastal site of the English Channel from 18S rDNA sequences.

Sensen, C.W., Heinmann, K. \& Melkonian, M. 1993. The production of clonal and axenic cultures of microalgae using fluorescence activated cell sorting. Eur. J. Phycol. 28:93-7.

Shi, X.L., Marie, D., Jardillier, L., Scanlan, D.J. \& Vaulot, D. 2009. Groups without cultured representatives dominate eukaryotic picophytoplankton in the oligotrophic South East Pacific Ocean. PLoS One. 4:e7657.

Sieracki, M., Poulton, N. \& Crosbie, N. 2005. Automated isolation techniques for microalgae. In Andersen, R. A. [Ed.] Algal Culturing Techniques. Academic Press, pp. 101-16.

Sinigalliano, C.D., Winshell, J., Guerrero, M.A., Scorzetti, G., Fell, J.W., Eaton, R.W., Brand, L. et al. 2010. Viable cell sorting of dinoflagellates by multiparametric flow. Phycologia. 48:249-57.

Sournia, A., Birrien, J.-L., Douville, J.-L., Klein, B. \& Viollier, M. 1987. A daily study of the diatom spring bloom at Roscoff (France) in 1985. I. The spring bloom within the annual cycle. Estuar. Coast. Shelf Sci. 25:355-67.

Sunagawa, S., Coelho, L.P., Chaffron, S., Kultima, J.R., Labadie, K., Salazar, G., Djahanschiri, B. et al. 2015. Structure and function of the global ocean microbiome. Science. 348:1261359-1261359.

Surek, B. \& Melkonian, M. 2004. CCAC - Culture Collection of Algae at the University of Cologne: A new collection of axenic algae with emphasis on flagellates. Nova Hedwigia. 79:77-92.

Vaulot, D., Le Gall, F., Marie, D., Guillou, L. \& Partensky, F. 2004. The Roscoff Culture Collection (RCC): a collection dedicated to marine picoplankton. Nova Hedwigia. 79:4970.

Woyke, T., Xie, G., Copeland, A., Gonzalez, J.M., Han, C., Kiss, H., Saw, J.H. et al. 2009. Assembling the marine metagenome, one cell at a time. PLoS One. 4:e5299.

Zubkov, M. V., Burkill, P.H. \& Topping, J.N. 2007. Flow cytometric enumeration of DNAstained oceanic planktonic protists. J. Plankton Res. 29:79-86. 
Marie et al. - Culture isolation by flow cytometry sorting - p. 23

\section{List of Tables}

534 Table 1 : List of pre-cultures obtained during the Atlantic Meridional Transect (AMT) cruise

535 \#24 in 2014 with station number, date and depth. Columns indicate whether enrichments were

536 established from pre-cultures (see Material and Methods), the number of single-cell flow

537 cytometry sorted wells and the number of dilution wells. For flow cytometry sorting, the type

538 of population sorted is indicated ( $\mathrm{P}$ for picoeukaryotes and $\mathrm{N}$ for nanoeukaryotes). The number

539 and percentage of positive wells obtained by the two techniques is also indicated. The position

540 of the stations is provided in Fig. 1.

\begin{tabular}{|c|c|c|c|c|c|c|c|c|c|c|c|}
\hline \multirow[t]{2}{*}{ Precultures } & \multirow{2}{*}{$\begin{array}{c}\text { Sampling } \\
\text { date }\end{array}$} & \multirow[t]{2}{*}{ Station } & \multirow[t]{2}{*}{ Depth } & \multirow[t]{2}{*}{ Enriched } & \multicolumn{4}{|c|}{ Sorted wells ( 1 cell per well) } & \multicolumn{3}{|c|}{ Dilution wells ( 10 cells per well) } \\
\hline & & & & & Pico/Nano & total & positive & $\%$ positive & total & positive & $\%$ positive \\
\hline AMT-04 & $27 / 09 / 2014$ & 4 & Surface & + & $\mathrm{N}$ & 40 & 36 & $90 \%$ & & & \\
\hline AMT-06 & 28/09/2014 & 6 & Surface & + & & & & & & & \\
\hline AMT-08 & $30 / 10 / 2014$ & 9 & Surface & & $\mathrm{P} / \mathrm{N}$ & 40 & 28 & $70 \%$ & 8 & 2 & $25 \%$ \\
\hline AMT-09 & $01 / 10 / 2014$ & 12 & 60 & & $\mathrm{~N}$ & 20 & 15 & $75 \%$ & 8 & 8 & $100 \%$ \\
\hline AMT-11 & $02 / 10 / 2014$ & 13 & 78 & + & & & & & & & \\
\hline AMT-12 & $02 / 10 / 2014$ & 13 & Surface & & $\mathrm{P} / \mathrm{N}$ & 40 & 13 & $33 \%$ & 8 & 3 & $38 \%$ \\
\hline AMT-13 & $03 / 10 / 2014$ & 15 & 100 & + & & & & & & & \\
\hline AMT-14 & $03 / 10 / 2014$ & 15 & Surface & + & & & & & & & \\
\hline AMT-16 & $04 / 10 / 2014$ & 18 & Surface & + & & & & & & & \\
\hline AMT-20 & $06 / 10 / 2014$ & 23 & Surface & & $\mathrm{N}$ & 20 & 1 & $5 \%$ & 8 & 4 & $50 \%$ \\
\hline AMT-25 & $10 / 10 / 2014$ & 33 & 45 & + & & & & & & & \\
\hline AMT-26 & $10 / 10 / 2014$ & 33 & Surface & & $\mathrm{N}$ & 20 & 0 & $0 \%$ & 8 & 1 & $13 \%$ \\
\hline AMT-27 & $11 / 10 / 2014$ & 35 & 75 & + & $P$ & 20 & 0 & $0 \%$ & 8 & 1 & $13 \%$ \\
\hline AMT-28 & $11 / 10 / 2014$ & 35 & Surface & & $\mathrm{N}$ & 20 & 15 & $75 \%$ & 8 & 2 & $25 \%$ \\
\hline AMT-30 & $12 / 10 / 2014$ & 38 & Surface & & $\mathrm{P} / \mathrm{N}$ & 40 & 5 & $13 \%$ & 8 & 8 & $100 \%$ \\
\hline AMT-32 & $14 / 10 / 2014$ & 42 & Surface & + & $\mathrm{P} / \mathrm{N}$ & 80 & 49 & $61 \%$ & & & \\
\hline AMT-36 & $16 / 10 / 2014$ & 48 & Surface & & $\mathrm{P} / \mathrm{N}$ & 60 & 16 & $27 \%$ & 8 & 1 & $13 \%$ \\
\hline AMT-42 & $20 / 10 / 2014$ & 56 & Surface & & $\mathrm{P}$ & 20 & 0 & $0 \%$ & 8 & 6 & $75 \%$ \\
\hline AMT-43 & $21 / 10 / 2014$ & 59 & 135 & + & $\mathrm{P}$ & 20 & 1 & $5 \%$ & & & \\
\hline AMT-44 & $21 / 10 / 2014$ & 59 & Surface & + & $\mathrm{N}$ & 20 & 2 & $10 \%$ & 8 & 0 & $0 \%$ \\
\hline AMT-46 & $22 / 10 / 2014$ & 62 & Surface & & $P$ & 20 & 6 & $30 \%$ & 8 & 3 & $38 \%$ \\
\hline AMT-47 & $23 / 10 / 2014$ & 65 & 87 & & & & & & & & \\
\hline AMT-48 & $23 / 10 / 2014$ & 65 & Surface & + & $\mathrm{P}$ & 20 & 13 & $65 \%$ & & & \\
\hline AMT-49 & $24 / 10 / 2014$ & 68 & 44 & + & $P$ & 20 & 12 & $60 \%$ & & & \\
\hline AMT-50 & $24 / 10 / 2014$ & 68 & Surface & + & $\mathrm{N}$ & 20 & 17 & $85 \%$ & & & \\
\hline AMT-51 & $25 / 10 / 2014$ & 71 & 50 & + & & & & & & & \\
\hline AMT-52 & $25 / 10 / 2014$ & 71 & Surface & + & $\mathrm{P}$ & 20 & 20 & $100 \%$ & & & \\
\hline AMT-53 & $26 / 10 / 2014$ & 73 & 40 & + & $\mathrm{N}$ & 20 & 3 & $15 \%$ & & & \\
\hline AMT-54 & $26 / 10 / 2014$ & 73 & Surface & & $\mathrm{P} / \mathrm{N}$ & 40 & 5 & $13 \%$ & 8 & 0 & $0 \%$ \\
\hline AMT-55 & $27 / 10 / 2014$ & 76 & 40 & & $\mathrm{P} / \mathrm{N}$ & 40 & 14 & $35 \%$ & 8 & 0 & $0 \%$ \\
\hline AMT-56 & $27 / 10 / 2014$ & 76 & Surface & + & $P$ & 20 & 5 & $25 \%$ & & & \\
\hline AMT-57 & $28 / 10 / 2014$ & 78 & 46 & + & & & & & & & \\
\hline AMT-58 & $28 / 10 / 2014$ & 78 & Surface & & $\mathrm{N}$ & 20 & 2 & $10 \%$ & 8 & 0 & $0 \%$ \\
\hline \multirow[t]{2}{*}{ Total } & \multicolumn{3}{|c|}{ Number of pre-cultures treated } & 19 & & 24 & & & 15 & & \\
\hline & \multicolumn{2}{|c|}{ Number of wells } & & & & 700 & 278 & $40 \%$ & 120 & 39 & $33 \%$ \\
\hline
\end{tabular}


Marie et al. - Culture isolation by flow cytometry sorting - p. 24

543 Table 2 : Evolution over two weeks of the numbers of positive wells (out of a total of 9 wells)

544 observed by epifluorescence on an inverted microscope after single-cell flow cytometry sorting

545 for $5 \mathrm{RCC}$ cultures. Cells were sorted into $1 \mathrm{~mL}$ of $\mathrm{K}$ medium with $\mathrm{BSA}$ at different

546 concentrations.

\begin{tabular}{|c|c|c|c|c|c|}
\hline Culture & BSA & Days 3 - 5 & Days 7 - 8 & Days $10-11$ & Day 14 \\
\hline \multirow[t]{4}{*}{ Micromonas pusilla RCC299 } & $0 \%$ & 0 & 0 & 0 & 0 \\
\hline & $0.01 \%$ & 9 & 9 & 9 & 9 \\
\hline & $0.10 \%$ & 4 & 4 & 4 & 4 \\
\hline & $0.50 \%$ & 5 & 5 & 5 & 5 \\
\hline \multirow[t]{4}{*}{ Florenciella sp. RCC1008 } & $0 \%$ & 0 & 0 & 0 & 1 \\
\hline & $0.01 \%$ & 0 & 0 & 0 & 0 \\
\hline & $0.10 \%$ & 0 & 1 & 2 & 2 \\
\hline & $0.50 \%$ & 0 & 2 & 5 & 7 \\
\hline \multirow[t]{4}{*}{ Isochrysis sp. RCC90 } & $0 \%$ & 7 & 8 & 8 & 8 \\
\hline & $0.01 \%$ & 4 & 9 & 9 & 9 \\
\hline & $0.10 \%$ & 5 & 9 & 9 & 9 \\
\hline & $0.50 \%$ & 5 & 6 & 7 & 7 \\
\hline \multirow[t]{4}{*}{ Rhodomonas baltica RCC350 } & $0 \%$ & 8 & 9 & 9 & 9 \\
\hline & $0.01 \%$ & 9 & 9 & 9 & 9 \\
\hline & $0.10 \%$ & 8 & 8 & 8 & 8 \\
\hline & $0.50 \%$ & 9 & 9 & 9 & 9 \\
\hline \multirow[t]{4}{*}{ Scrippsiella sp. RCC4108 } & $0 \%$ & 5 & 5 & 5 & 5 \\
\hline & $0.01 \%$ & 0 & 2 & 4 & 4 \\
\hline & $0.10 \%$ & 3 & 3 & 3 & 3 \\
\hline & $0.50 \%$ & 2 & 3 & 3 & 3 \\
\hline
\end{tabular}


Marie et al. - Culture isolation by flow cytometry sorting - p. 25

548 Table 3 : Percentage of positive wells (out of 45 wells) obtained from single cell sorting by flow

549 cytometry of picoeukaryotes and nanoeukaryotes into four different media from a natural

550 sample from the English Channel off Roscoff taken in May 2015.

\begin{tabular}{|c|c|c|c|c|c|c|}
\hline \multirow[b]{2}{*}{ Population } & \multirow[b]{2}{*}{ Medium } & \multicolumn{5}{|c|}{ Day } \\
\hline & & 3 & 6 & 9 & 12 & 15 \\
\hline \multirow[t]{4}{*}{ Picoeukaryotes } & SW & $33 \%$ & $47 \%$ & $51 \%$ & $62 \%$ & $69 \%$ \\
\hline & $\mathrm{SW}+\mathrm{Nut}$ & $33 \%$ & $56 \%$ & $71 \%$ & $78 \%$ & $80 \%$ \\
\hline & $\mathrm{f} / 2$ & $24 \%$ & $84 \%$ & $98 \%$ & $98 \%$ & $98 \%$ \\
\hline & $\mathrm{K}$ & $7 \%$ & $22 \%$ & $36 \%$ & $49 \%$ & $51 \%$ \\
\hline & & & & & & \\
\hline \multirow[t]{4}{*}{ Nanoeukaryotes } & SW & $27 \%$ & $60 \%$ & $69 \%$ & $69 \%$ & $71 \%$ \\
\hline & $\mathrm{SW}+\mathrm{Nut}$ & $18 \%$ & $60 \%$ & $67 \%$ & $67 \%$ & $67 \%$ \\
\hline & $\mathrm{f} / 2$ & $20 \%$ & $51 \%$ & $60 \%$ & $60 \%$ & $60 \%$ \\
\hline & $\mathrm{K}$ & $16 \%$ & $33 \%$ & $47 \%$ & $49 \%$ & $49 \%$ \\
\hline
\end{tabular}


Marie et al. - Culture isolation by flow cytometry sorting - p. 26

553 Table 4 : Comparison of the taxonomic identity of cultures isolated by single cell flow

554 cytometry sorting of picoeukaryotes and nanoeukaryotes into four different media of a natural

555 sample from the English Channel off Roscoff taken in May 2015.

\begin{tabular}{|c|c|c|c|c|c|c|}
\hline \multirow[b]{2}{*}{ Division } & \multirow[b]{2}{*}{ Class } & \multirow[b]{2}{*}{ Genus } & \multicolumn{4}{|c|}{ Medium } \\
\hline & & & SW & SW+Nut & $f / 2$ & K \\
\hline & & & \multicolumn{4}{|c|}{ Picoeukaryotes } \\
\hline Chlorophyta & Mamiellophyceae & Ostreococcus & & & & \\
\hline Chlorophyta & Mamiellophyceae & Micromonas & & & & \\
\hline Chlorophyta & Mamiellophyceae & Bathycoccus & & & & \\
\hline \multirow[t]{3}{*}{ Chlorophyta } & Trebouxiophyceae & Picochlorum & & & & \\
\hline & & & & & & \\
\hline & & & \multicolumn{4}{|c|}{ Nanoeukaryotes } \\
\hline Heterokontophyta & Coscinodiscophyceae & Minidiscus & & & & \\
\hline Heterokontophyta & Coscinodiscophyceae & Thalassiosira & & & & \\
\hline Haptophyta & Prymnesiophyceae & Phaeocystis & & & & \\
\hline Heterokontophyta & Mediophyceae & Minutocellus & & & & \\
\hline Heterokontophyta & Mediophyceae & Unknown & & & & \\
\hline Heterokontophyta & Bacillariophyceae & Cylindrotheca & & & & \\
\hline
\end{tabular}


558 Table 5: List of cultures isolated from the AMT transect by single-cell flow cytometry sorting,

559 serial dilution and enrichment.

\begin{tabular}{|c|c|c|c|c|c|c|c|}
\hline Precultures & Isolation & Division & Class & Order & Genus & $\begin{array}{c}\text { Number of } \\
\text { cultures }\end{array}$ & RCC id \\
\hline AMT-04 & Cell sorting & Haptophyta & Prymnesiophyceae & Phaeocystales & Phaeocystis & 1 & LOST \\
\hline AMT-06 & Enrichment & Cyanophyta & Cyanophyceae & Synechococcales & Synechococcus & 1 & LOST \\
\hline AMT-08 & Dilution & Heterokontophyta & Pelagophyceae & Pelagomonadales & Pelagomonas & 1 & 4548 \\
\hline AMT-08 & Cell sorting & Haptophyta & Prymnesiophyceae & Isochrysidales & Emiliania & 1 & 4549 \\
\hline AMT-09 & Dilution & Haptophyta & Prymnesiophyceae & Phaeocystales & Phaeocystis & 1 & LOST \\
\hline AMT-11 & Enrichment & Cyanophyta & Cyanophyceae & Synechococcales & Synechococcus & 1 & 4550 \\
\hline AMT-12 & Dilution & Heterokontophyta & Pelagophyceae & Pelagomonadales & Pelagomonas & 1 & 4551 \\
\hline AMT-12 & Cell sorting & Heterokontophyta & Pelagophyceae & Pelagomonadales & New species 1 & 1 & 4552 \\
\hline AMT-12 & Enrichment & Chlorophyta & Prasinophyceae & Clade VIIA3 & Undescribed & 1 & 4553 \\
\hline AMT-13 & Enrichment & Cyanophyta & Cyanophyceae & Synechococcales & Synechococcus & 1 & 4554 \\
\hline AMT-14 & Enrichment & Cyanophyta & Cyanophyceae & Synechococcales & Synechococcus & 1 & 4555 \\
\hline AMT-16 & Enrichment & Cyanophyta & Cyanophyceae & Synechococcales & Synechococcus & 1 & LOST \\
\hline AMT-20 & Dilution & Heterokontophyta & Pelagophyceae & Pelagomonadales & Pelagomonas & 2 & LOST \\
\hline AMT-25 & Enrichment & Cyanophyta & Cyanophyceae & Synechococcales & Synechococcus & 1 & 4556 \\
\hline AMT-26 & Dilution & Cyanophyta & Cyanophyceae & Synechococcales & Synechococcus & 1 & 4557 \\
\hline AMT-27 & Enrichment & Heterokontophyta & Chrysophyceae & Chromulinales & Spumella & 1 & 4558 \\
\hline AMT-27 & Dilution & Heterokontophyta & Pelagophyceae & Pelagomonadales & Pelagomonas & 1 & 4559 \\
\hline AMT-28 & Dilution & Heterokontophyta & Pelagophyceae & Pelagomonadales & Pelagomonas & 1 & LOST \\
\hline AMT-30 & Dilution & Bacillariophyta & Bacillariophyceae & Bacillariales & Pseudo-nitzschia & 1 & LOST \\
\hline AMT-30 & Cell sorting & Haptophyta & Prymnesiophyceae & Isochrysidales & Emiliania & 1 & 4560 \\
\hline AMT-30 & Cell sorting & Heterokontophyta & Pelagophyceae & Pelagomonadales & Pelagomonas & 1 & 4561 \\
\hline AMT-32 & Cell sorting & Heterokontophyta & Pelagophyceae & Pelagomonadales & New species 2 & 2 & 4562,4563 \\
\hline AMT-32 & Cell sorting & Heterokontophyta & Pelagophyceae & Pelagomonadales & Pelagomonas & 1 & 4564 \\
\hline AMT-32 & Dilution & Chlorophyta & Prasinophyceae & Clade VII & Unknown & 1 & 4565 \\
\hline AMT-32 & Cell sorting & Haptophyta & Prymnesiophyceae & Phaeocystales & Phaeocystis & 1 & LOST \\
\hline AMT-36 & Dilution & Heterokontophyta & Pelagophyceae & Pelagomonadales & Pelagomonas & 1 & 4566 \\
\hline AMT-36 & Cell sorting & Haptophyta & Prymnesiophyceae & Isochrysidales & Emiliania & 1 & 4567 \\
\hline AMT-42 & Dilution & Chlorophyta & Prasinophyceae & Clade VII & Undescribed & 1 & 4568 \\
\hline AMT-42 & Dilution & Chlorophyta & Prasinophyceae & Clade VIIA3 & Undescribed & 1 & 4569 \\
\hline AMT-43 & Enrichment & Heterokontophyta & Novel class RCC 853 & Undescribed & Undescribed & 1 & 4570 \\
\hline AMT-44 & Enrichment & Cyanophyta & Cyanophyceae & Synechococcales & Synechococcus & 1 & 4571 \\
\hline AMT-46 & Dilution & Chlorophyta & Prasinophyceae & clade VIIB3 & Undescribed & 1 & 4572 \\
\hline AMT-46 & Dilution & Chlorophyta & Prasinophyceae & clade VIIA4 & Undescribed & 1 & 4573 \\
\hline AMT-48 & Cell sorting & Chlorophyta & Mamiellophyceae & Mamiellales & Micromonas & 1 & 4574 \\
\hline AMT-49 & Cell sorting & Chlorophyta & Mamiellophyceae & Mamiellales & Micromonas & 2 & LOST \\
\hline AMT-50 & Cell sorting & Haptophyta & Prymnesiophyceae & Prymnesiales & Imantonia & 2 & 4575,4576 \\
\hline AMT-52 & Enrichment & Chlorophyta & Mamiellophyceae & Mamiellales & Micromonas & 1 & LOST \\
\hline AMT-52 & Cell sorting & Chlorophyta & Trebouxiophyceae & Unknown & Unknown & 3 & LOST \\
\hline AMT-53 & Enrichment & Haptophyta & Prymnesiophyceae & Phaeocystales & Phaeocystis & 1 & LOST \\
\hline AMT-54 & Cell sorting & Haptophyta & Prymnesiophyceae & Prymnesiales & Imantonia & 1 & 4577 \\
\hline AMT-55 & Cell sorting & Chlorophyta & Mamiellophyceae & Mamiellales & Micromonas & 2 & LOST \\
\hline AMT-56 & Cell sorting & Chlorophyta & Mamiellophyceae & Mamiellales & Micromonas & 2 & LOST \\
\hline AMT-57 & Enrichment & Haptophyta & Prymnesiophyceae & Prymnesiales & Imantonia & 1 & 4578 \\
\hline AMT-58 & Cell sorting & Haptophyta & Prymnesiophyceae & Phaeocystales & Phaeocystis & 1 & 4579 \\
\hline
\end{tabular}


Marie et al. - Culture isolation by flow cytometry sorting - p. 28

562 Table 6 : Comparison of the taxonomic identity of the cultures obtained by single-cell flow

563 cytometry sorting vs. dilution or enrichment.

\begin{tabular}{|c|c|c|c|c|c|c|}
\hline Division & Class & Genus & $\begin{array}{l}\text { Number of pre- } \\
\text { cultures where } \\
\text { genus isolated }\end{array}$ & Cell Sorting & Dilution & Enrichment \\
\hline Bacteria & Cyanophyceae & Synechococcus & 8 & & & \\
\hline Heterokontophyta & Pelagophyceae & Pelagomonas & 8 & & & \\
\hline Chlorophyta & Mamiellophyceae & Micromonas & 5 & & & \\
\hline Haptophyta & Prymnesiophyceae & Phaeocystis & 5 & & & \\
\hline Chlorophyta & Prasinophyceae & clade VII & 4 & & & \\
\hline Haptophyta & Prymnesiophyceae & Emiliania & 3 & & & \\
\hline Haptophyta & Prymnesiophyceae & Imantonia & 3 & & & \\
\hline Heterokontophyta & Pelagophyceae & Undescribed & 2 & & & \\
\hline Chlorophyta & Trebouxiophyceae & Unknown & 1 & & & \\
\hline Heterokontophyta & Bacillariophyceae & Pseudo-nitzschia & 1 & & & \\
\hline Heterokontophyta & Chrysophyceae & Spumella & 1 & & & \\
\hline Heterokontophyta & Unknown RCC853 & Unknown & 1 & & & \\
\hline & & \multicolumn{2}{|c|}{ Total number of genera isolated } & 8 & 5 & 6 \\
\hline
\end{tabular}


Marie et al. - Culture isolation by flow cytometry sorting - p. 29

566

567 Figure 1: Cruise track of Atlantic Meridional Transect \# 24 in 2014 with the location of sampled 568 stations.

569 Figure 2: Effect of the concentration of BSA on the recovery of RCC cultures after sorting of 5701000 cells of Micromonas pusilla RCC299 (A), Isochrysis sp. RCC90 (B), Rhodomonas baltica 571 RCC350 (C), and Florenciella sp. RCC1008 (D), and 500 cells of Scrippsiella sp. RCC4108 572 (E) into $1 \mathrm{~mL}$ of $\mathrm{K}$ medium. Cell concentration was followed by flow cytometry. Error bars 573 correspond to the standard error from three replicates.

574 Figure 3: Evolution of cell concentration for 1000 cells of Micromonas pusilla RCC299 (A), 575 Isochrysis sp. RCC90 (B), Rhodomonas baltica RCC350 (C), Florenciella sp. RCC1008 (D), 576 replicates. 
Marie et al. - Culture isolation by flow cytometry sorting - p. 30 


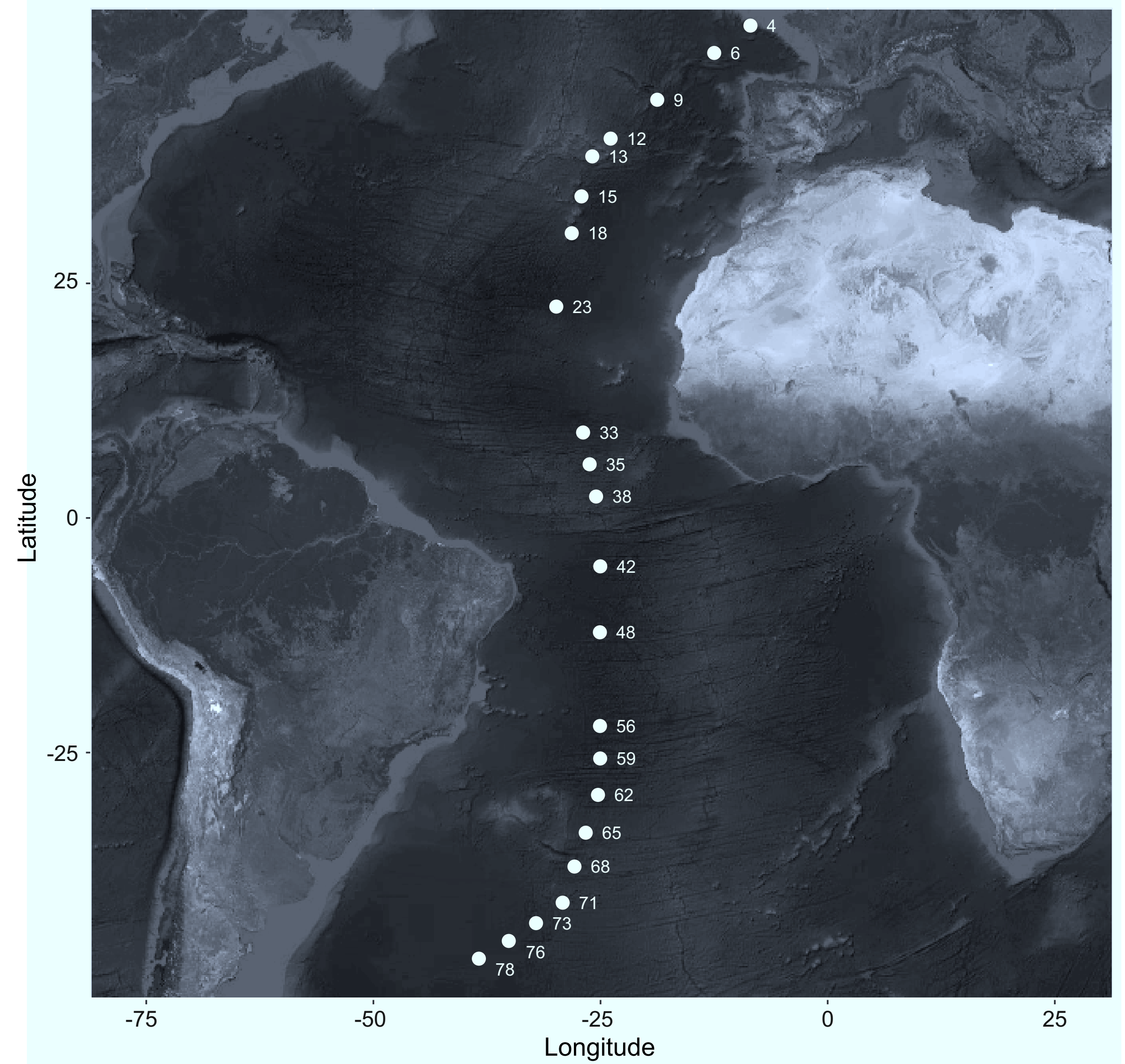




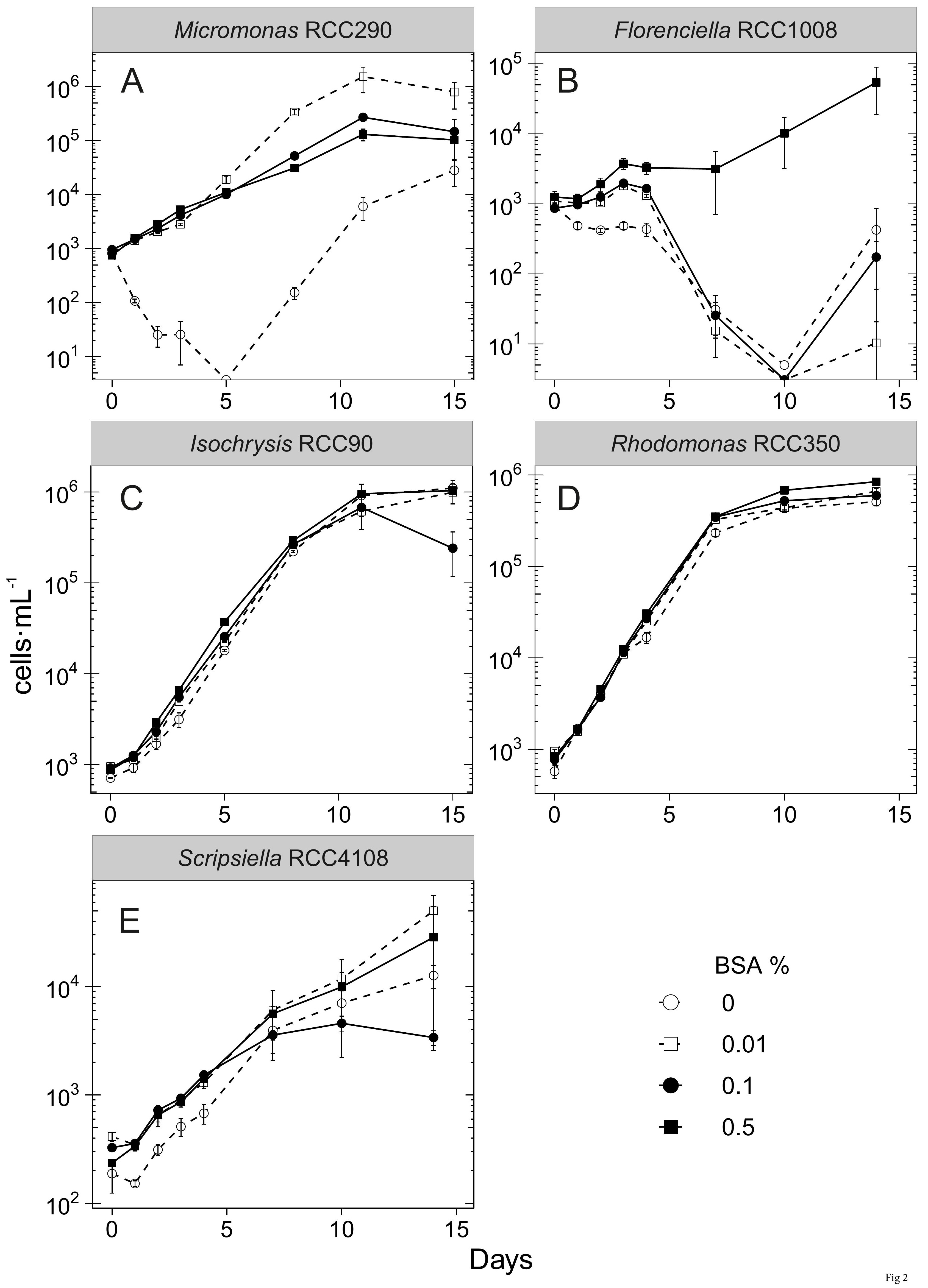



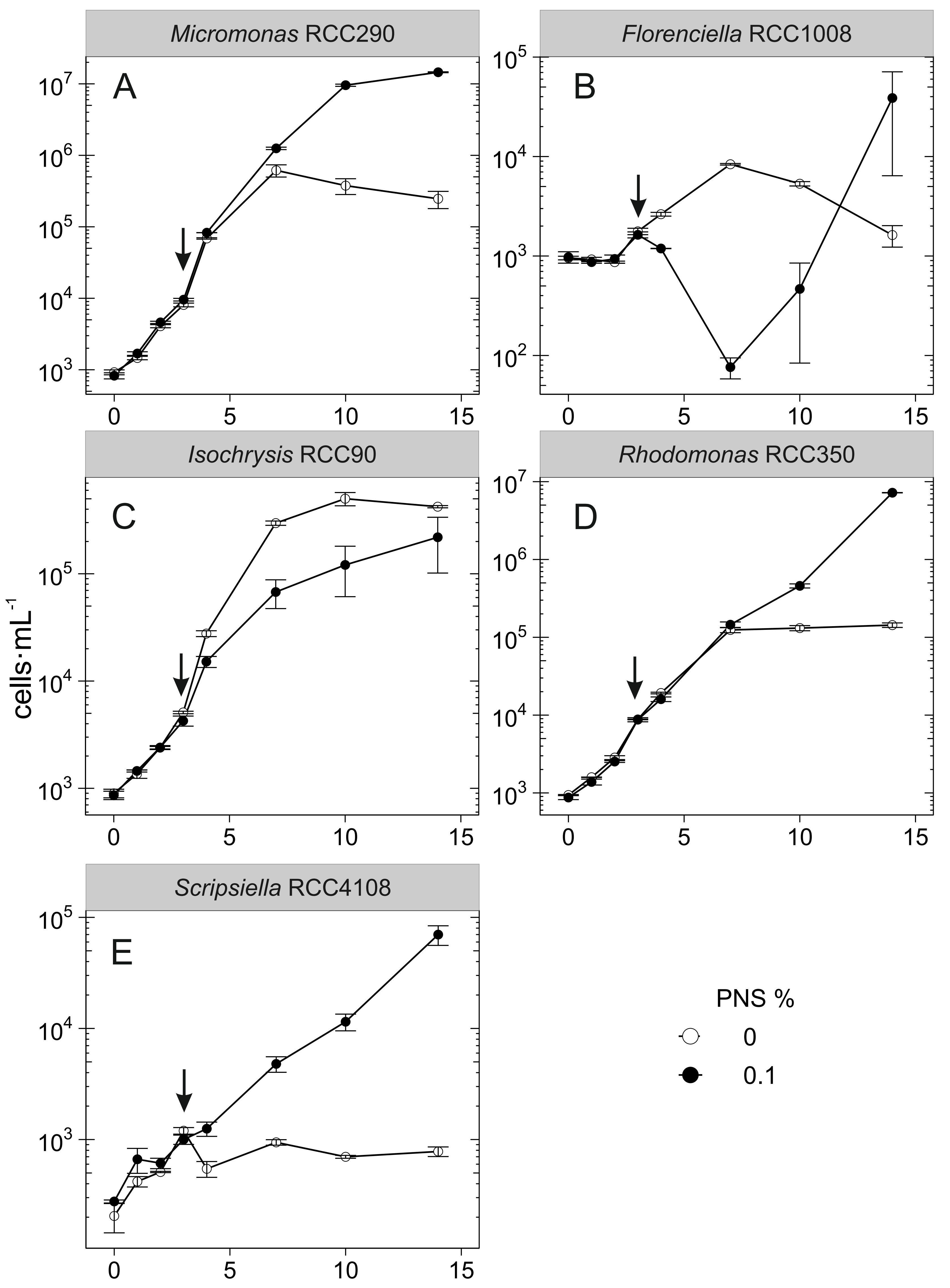

\section{Days}




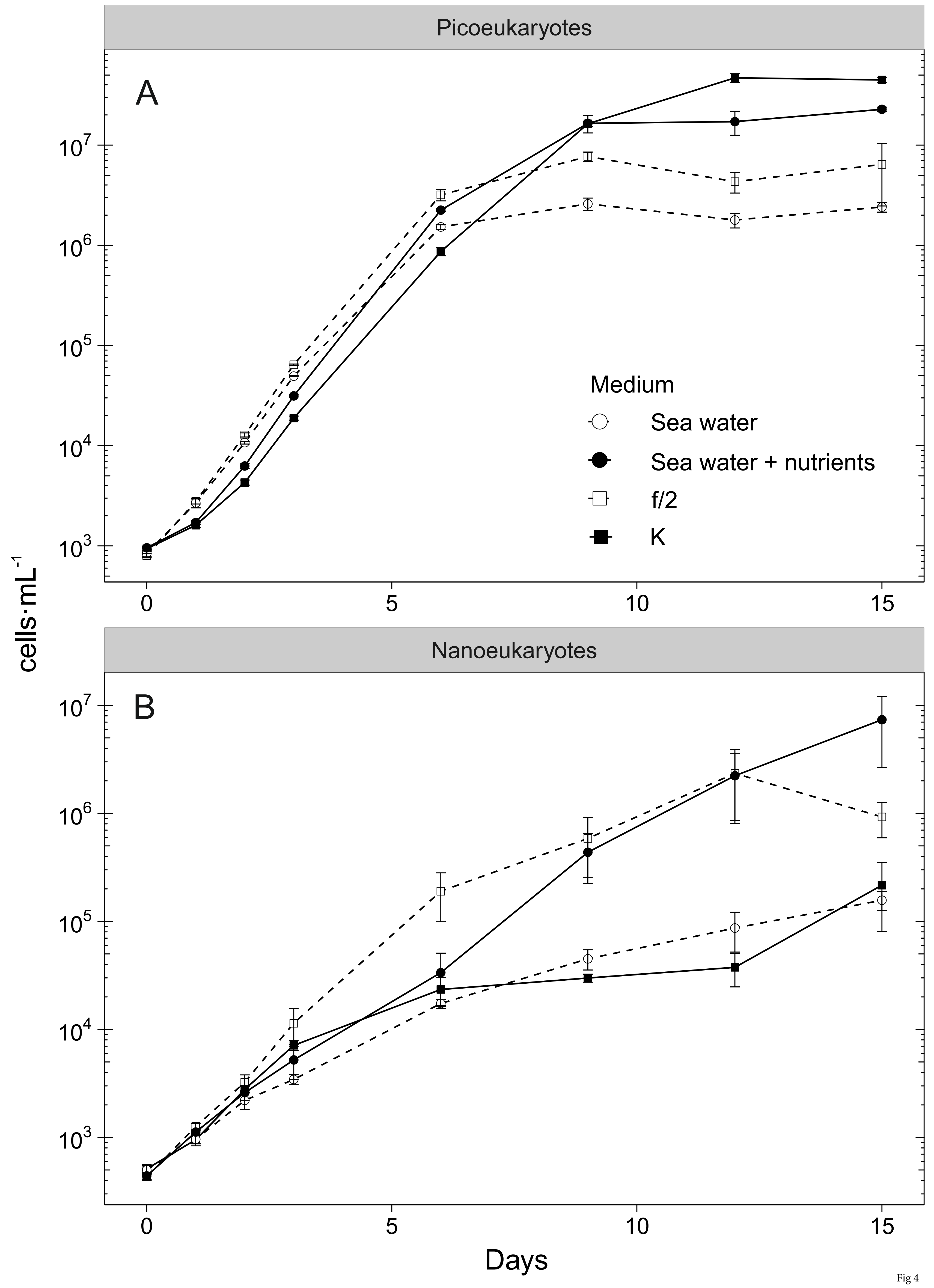

